\title{
Tradição oral e patrimônio imaterial: o papel da memória na luta por políticas públicas na Comunidade de Canárias, Maranhão
}

\author{
Oral tradition and intangible heritage: \\ the role of memory in the fight for public policy in the \\ Community of Canárias, Maranhão
}

\section{Marta Gouveia De Oliveira Rovai}

\begin{abstract}
Doutora em História Social pela Universidade de São Paulo (USP),professora-adjunta da Universidade Federal de Alfenas (Unifal), pesquisadora do Núcleo de Estudos em História Oral (NEHO/USP) e Núcleo de Pesquisa Cidade, Cultura e Identidade (CCI), da Universidade Estadual do Piauí
\end{abstract}

\section{Resumo}

Este artigo trata de pesquisa com comunidades de pescadores da ilha das Canárias, na região do Delta do Parnaíba, Maranhão. O ensino às novas gerações de técnicas, histórias e mitos, seus festejos e associações são manifestações não apenas de tradições que se perpetuam, mas têm se mostrado também estratégias coletivas de adaptação ou resistência contra o avanço de dificuldades de sobrevivência impostas pela especulação imobiliária e o turismo desenfreado nos chamados "espaços paradisíacos". Nesse sentido, a organização dessas comunidades para a conservação de seus ritos, práticas e conhecimentos são mecanismos de conscientização e de reivindicação política em busca do reconhecimento e da conservação de sua cultura imaterial e, consequentemente, da criação de políticas públicas de caráter participativo e democrático.

Palavras-chave: memória - cultura imaterial - políticas públicas

\section{Abstract}

This article treats of the research on communities of fishermen of the Canarias's Islands, in the region of the Parnaíba's Delta, Maranhão. The teaching of the techniques, myths and stories to the new generations, their celebrations and associations are ----- not only of traditions that perpetuate, but it has been shown also collective strategies of adaptation and resistance against the grown of difficulties of survival caused by imobiliary speculation and unbridled tourism in "heavenly spaces", as they are called. Therefore, the organization of these communities for the conservation of their rites, practices and knowledge are mechanisms of awareness and political demand in search of recognition and conservation of their incorporeal culture and, consequently, in search of the creation of participatory and democratic public politics.

Keywords: memory - imaterial culture - public politics 


\section{Introdução}

No ano de 2013, desenvolvi um trabalho de pesquisa com alunos da Universidade Estadual do Piauí, membros do Núcleo de Pesquisa Cidade, Cultura e Identidade (CCI), sobre memória e patrimônio cultural material/ imaterial na ilha das Canárias, município de Araioses, no Maranhão. Nessa região forma-se o Delta do Rio Parnaiba, que faz a divisa entre este estado e o Piauí e cuja paisagem natural conta com várias outras ilhas, muitas dunas e igarapés. A região pertence à Área de Preservação Ambiental (APA) como Unidade de Conservação de Uso Direto, criada pelo governo federal, e está sob cuidados do Instituto Chico Mendes (ICMBio), órgão do Instituto Brasileiro do Meio Ambiente (Ibama) e do Instituto Nacional de Reforma Agrária (Incra).

Ali vivem pescadores, barqueiros, artesãos e catadores de caranguejo, numa profunda relação com as águas do mar e do rio, a partir das quais tiram seu alimento, constroem seu cotidiano, seus medos e sonhos. No Rio Parnaíba navegam, transportam pessoas, levam e trazem mercadorias e também vislumbram o futuro de seus filhos nas cidades próximas - Ilha Grande e Parnaíba, no Piauí - em busca de escolas, postos de saúde e outras formas de trabalho.

A população vive essencialmente da pesca, da cata de caranguejo e da produção de artefatos que auxiliam em seu ofício ou que são comercializados nas cidades vizinhas, como forma de sustento de suas famílias. Barcos, redes, vassouras, balaios, cofos e tarrafas, além de todo artesanato com palha de buriti ou carnaúba e de doces de caju, fazem parte do dia a dia dos moradores, que podem ser vistos reunidos na praça ou na porta de suas casas, partilhando seus saberes e afazeres. A feitura da rede, o artesanato com a palha e a madeira, a referência aos mitos e à religiosidade que se misturam em suas narrativas, tudo faz parte de um patrimônio cultural que se manifesta na memória e na tradição. Novas gerações rodeiam seus pais e avós para assisti-los e aprender com eles, dando significado ao que ainda permanece unindo e fortalecendo a identidade comunitária.

Nos últimos anos, essa população ribeirinha tem assistido a uma série de mudanças socioambientais que tem alterado, em parte, sua maneira de trabalhar, morar e viver, suas relações com a natureza. $\mathrm{O}$ turismo crescente provoca expectativas de melhoria na vida econômica e, ao mesmo tempo, o processo de avanço das dunas de areia que têm assoreado o rio devido ao desmatamento, promove temores quanto à intervenção de pessoas fora da comunidade no meio ambiente e em sua cultura tradicional.

\section{A pesquisa com memória e patrimônio imaterial/intangível}

Em 1989, a Unesco elaborou a Recomendação sobre a Salvaguarda da Cultura e Tradição Popular, levando em conta a importância dos modos de viver, saberes e fazeres das comunidades tradicionais, consideradas "tesouro da humanidade". ${ }^{1}$ No ano de 1993, declarou que as comunidades portadoras da tradição deveriam ser salvaguardadas por sua fragilidade diante dos empreendimentos capitalistas que se apropriam de sua produção, comercialização e até mesmo do direito autoral sobre os bens criados. A Unesco considerou que os portadores desse patrimônio pudessem continuar transmitindo-o às novas gerações, produzindo-o e decidindo sobre seus usos, significados e funções, e que o Estado deveria ter papel fundamental na criação de políticas públicas que garantissem esse processo.

Nesse sentido, o governo brasileiro instituiu, em 2000, o Registro dos Bens Culturais de Natureza Imaterial e criou o Programa Nacional de Patrimônio Imaterial, com o Inventário Nacional de Referências Culturais (INRC), sob a orientação do IPHAN ${ }^{2}$, abarcando paisagens naturais, artes, ofícios, expressões, festas e lugares a que a memória social atribui sentido, pertencimento, afetividade e raízes. A oralidade passou a ser considerada, dessa forma, importante elo entre as gerações, pela qual a tradição poderia ser transmitida e valorizada.

A memória expressa por membros de grupos tradicionais, no que diz respeito à produção e à apropriação de seus saberes, fazeres e hábitos, permite uma noção muito mais ampla de herança cultural do que a concepção restrita de patrimônio atribuída aos monumentos materiais e coloca nova perspectiva sobre a decisão do

1 Documento da Unesco, de 2003, ratificou e defendeu a salvaguarda do patrimônio imaterial das chamadas populações tradicionais, englobando-a ao patrimônio mundial.

2 O Instituto de Patrimônio Histórico e Artístico Nacional (IPHAN) foi criado em 1937, durante o governo do presidente Getúlio Vargas, preocupado com o levantamento de monumentos que pudessem representar a "cultura nacional". 
que deve ser conservado e preservado. Para José Reginaldo Santos Gonçalves (2005), a divisão entre patrimônio material e imaterial, na vivência cotidiana, é inexistente, e a escolha pela sua continuidade não deve seguir apenas critérios de especialistas, muitas vezes externos à própria comunidade. O patrimônio deve ser entendido como algo muito mais dinâmico e vivo, referência cultural de pertencimento e unidade; senão corre-se o risco de impor sobre a coletividade uma ideia de tradição e de memória abstrata e arbitrária, que não corresponde à experiência, aos seus anseios e valores, promovendo sua rejeição. Sobre isso, o autor afirma:

O que essa experiência de rejeição parece colocar em foco é menos a relatividade das concepções de patrimônio nas sociedades modernas (...) e mais o fato de que um patrimônio não depende apenas da vontade e decisão políticas de uma agência de Estado. Nem depende exclusivamente de uma atividade consciente e deliberada de indivíduos ou grupos. Os objetos que compõem um patrimônio precisam encontrar "ressonância" junto a seu público. (GONÇALVES, 2005: p.19)

A ressonância sobre a qual fala Gonçalves remete ao reconhecimento, por parte da comunidade, dos bens materiais ou intangíveis como manifestação de sua cultura e de seu entendimento de mundo. Isto significa que a ideia de patrimônio implica não apenas a concepção de posse, mas os sentidos e valores constituídos pelas relações e experiências coletivas. Não cabe ao intelectual decidir, a priori, o que importa preservar para determinado grupo, mas entender o que é patrimônio para seus membros, quem são os sujeitos que partilham seus saberes e afazeres; e como se dão a circulação, a apropriação e o acesso das pessoas àquilo que elas mesmas produziram.

Por isso, houve a necessidade de observação atenta ao cotidiano dos moradores das Canárias por parte dos membros do Núcleo de Pesquisa Cidade, Cultura e Identidade, além das conversas em grupo e individuais para "mergulhar", em parte, na experiência dos trabalhadores ligados ao mar e ao rio. O projeto de história oral permitiu que ao longo do ano pudéssemos exercitar os ouvidos e os olhos, na tentativa de perceber as trocas geracionais, os momentos de aprendizagem na areia, na água e nas embarcações.

Esse tipo de investigação qualitativa exigiu períodos de permanência e convivência com a coletividade, além de entrevistas abertas, temáticas, com estímulos aos narradores. Mais do que fatos, foi preciso uma análise sobre os discursos dos narradores, com suas marcas: silêncios, reticências, distorções, mentiras, esquecimentos, valorizações, negociações e resistências. Em diferentes momentos, pudemos observar gestos e comportamentos rotineiros que nos revelaram não apenas a materialidade dos ofícios com a palha, a madeira ou a pesca, mas também as significações simbólicas, estéticas e sociais de seus usos, as relações sociais e de gênero, a religiosidade, os festejos, os lugares de memória e de pertencimento.

Os relatos dos ribeirinhos mostraram o desejo coletivo de que certas práticas permaneçam em seu cotidiano, não apenas como hábito, e sim como referências culturais que os constituem como indivíduos singulares que se recriam socialmente e dão sentido ao mundo ${ }^{3}$. Assim são as festas dedicadas aos santos João e José, padroeiros da comunidade, os encontros para a troca de conhecimento e para o trabalho solidário, como a feitura ou o conserto das redes.

A oralidade e a observação têm papel fundamental nas relações de aprendizado entre as gerações, sendo os mecanismos pelos quais essa gama de conhecimento é repassada. $\mathrm{O}$ trabalho com a pesca e suas atividades correlatas apareceu nos relatos dos pescadores entrevistados como aspecto central dessa memória e da identidade das Canárias. No olhar atento e diário das novas gerações, que muitas vezes acompanham os adultos enquanto tecem redes e tarrafas, ou realizam a pesca diária, é que meninos e meninas se familiarizam com as atividades, assimilando-as e reproduzindo-as nas brincadeiras. As conversas informais entre pais/avós e filhos/netos, nas casas ou nas praças, exercem a função de preencher as lacunas deixadas pela observação.

Para Amorozo, o diálogo entre as gerações é de fundamental importância, no sentido de conservar essas práticas tradicionais:

Em sociedades tradicionais, a transmissão oral é o principal modo pelo qual o conhecimento é perpetuado. O co-

3 "Referências são as edificações e são paisagens naturais. São também as artes, os ofícios, as formas de expressão e os modos de fazer. São as festas e os lugares a que a memória e a vida social atribuem sentido diferenciado: são as consideradas mais belas, são as mais lembradas, as mais queridas. São fatos, atividades e objetos que mobilizam a gente mais próxima e que reaproximam os que estão longe, para que se reviva o sentimento de participar e de pertencer a um grupo, de possuir um lugar. Em suma, referências são objetos, práticas e lugares apropriados pela cultura na construção de sentidos de identidade, são o que popularmente se chama de raiz de uma cultura.” In: Iphan. Inventário Nacional de Referências Culturais. Manual de Aplicação. Fev./2000. 
nhecimento é transmitido em situações, o que faz que a transmissão entre gerações requeira contato prolongado dos membros mais velhos com os mais novos. (AMOROZO, 1996: p. 11)

O que os entrevistados por vezes evidenciaram, no entanto, foi o fato de que esses momentos de diálogos mais demorados e profundos estejam se escasseando, uma vez que a temporalidade mais veloz e os novos desejos de consumo atraem os jovens para outras práticas e estes pouco manifestam interesse em ouvir os mais velhos. A pesca artesanal, por exemplo, praticada pela maioria dos moradores das Canárias, restringe-se cada vez mais aos adultos, embora garanta a sobrevivência e represente a maior parte da renda das famílias. Segundo Diegues (1999), essa atividade ainda representa no Brasil uma das mais importantes para a vida prática e para a geração de conhecimentos que ajudam a construir a identidade coletiva das comunidades pesqueiras. Os ribeirinhos

praticam a pequena pesca, cuja produção em parte é consumida pela família e em parte é comercializada. A unidade de produção é, em geral, a familiar, incluindo na tripulação conhecidos e parentes mais longínquos. (DIEGUES, 1999: p.11)

Esse aspecto pode ser percebido na maior parte das narrativas dos moradores das Canárias, apresentando a pesca de peixes e camarões, ou mesmo a coleta de caranguejos, como fonte principal de renda, compondo a base alimentar familiar, e também possibilitando o convívio e a aprendizagem constante, além da garantia de futuro aos seus filhos. Embora desejem que os mais jovens valorizem seus saberes artesanais, muitos pais reconhecem a necessidade de que eles estudem, trazendo, inclusive, benefícios à comunidade a partir de seus conhecimentos acadêmicos e técnicos.

Mesmo reconhecendo o valor da universidade como algo importante, os entrevistados demonstraram satisfação e orgulho ao narrarem sobre seus afazeres em torno daquilo que sabem e que gostariam que fosse reconhecido e conservado não só pelos mais novos, mas também pelas organizações - ICMBio, Incra, Ibama e ONGs - que interferem na vivência da ilha com seus projetos ambientalistas.

A tecnologia trazida "por instituições de fora" colaborou para a introdução de embarcações motorizadas, no lugar dos barcos a vela, ajudando também na rapidez maior quanto ao transporte de pessoas - principalmente turistas que chegam à região - e à agilização da pesca. Essa nova dinâmica fez com que a maioria da população abandonasse os roçados de arroz e se dedicasse quase exclusivamente à pesca e atividades artesanais ligadas a ela, como a produção da tarrafa, da rede, da caçoeira, do curral, do jiqui, do landoá e do puçá, guardados em tendas nos quintais das casas, feitas com barro ou madeira e cobertas por palha de carnaúba.

A maior parte dessas atividades é realizada por adultos, a maioria nascida na própria comunidade das Canárias, apontada por eles como um limite à oportunidade de outras formas de sobrevivência. Pelo contrário, os jovens acabaram tendo novas opções em cidades próximas, principalmente por meio de políticas públicas, como o aumento de vagas nas universidades da região, o acesso ao transporte fluvial e o estímulo ao desenvolvimento do turismo, por projetos da Embratur, como "O Roteiro das Emoções” no Delta do Rio Parnaíba. Os conhecimentos ligados à pesca, entretanto, ainda continuam a ser transmitidos entre as gerações, o que pode ser observado pelo fato deque os jovens, embora tenham a tendência a sair das Canárias em direção à Ilha Grande e Parnaíba, no Piauí, em busca de outros empregos ou da continuidade de seus estudos, também confeccionam seus próprios instrumentos, pescam ou ajudam seus familiares na manutenção das práticas artesanais. Nas praças, nas margens do Rio Parnaíba ou na porta de suas residências, dão continuidade a um saber coletivo e familiar.

\section{A tradição oral e cultura imaterial/intangível}

A narrativa em torno dos saberes e fazeres torna o sexo masculino um "grupo autorizado" a falar sobre essas práticas, num quase "enquadramento" de memória e dos conhecimentos tradicionais, como diria Michael Pollak (1992), com exceção para algumas poucas mulheres que, embora possam saber sobre a pesca e o artesanato, não são consideradas conhecedoras das técnicas ${ }^{4}$. De modo geral, as atividades da pesca e das embarcações são tradicionalmente desempenhadas pelos homens, que pouco permitem que suas esposas

4 Michael Pollak (1992) afirmou que em certas comunidades, alguns grupos tendem a construir um discurso coletivo autorizado, colocando-se como porta-voz de uma memória reconhecida. Considero que não se trata de "enquadramento" de memória, pois isso pressupõe a fixação de uma memória, que é sempre viva, mas uma tentativa de preservar uma versão. 
falem sobre elas. O grupo de pesquisadores chegou a presenciar, inclusive, cenas em que maridos proibiam suas companheiras de nos darem entrevistas, considerando-as incapazes para fazê-lo.

As catadoras de mariscos e caranguejos, as vendedoras de peixes e/ou artesanatos e as artesãs costumam ajudar seus maridos, pescadores, a salgar o produto da pesca, a tecer redes e produzir tarrafas e outros artefatos, mas não são estimuladas a sair pelo mar, seja pelo perigo que ele representa ou pelo fato de considerarem que suas funções devam restringir-se à casa e aos trabalhos domésticos. O rio mais doce e suave, no imaginário dos pescadores, pode ser, em certas circunstâncias, espaço feminino; o mar, considerado traiçoeiro e grandioso, é lugar exclusivo dos homens.

Isso é revelador também de uma forma de entender o mundo e de uma conduta coletiva que merecem ser pensados como tradição, compreendidos não por ser algo dado e sim permanência em meio a uma série de mudanças que atingem o cotidiano das famílias. As relações de gênero, entendidas como construções contínuas de poder, emergiram nas narrativas no sentido de que o sexo feminino começa a questionar a submissão "naturalizada". 5

Além da pesca e das embarcações, os entrevistados e as entrevistadas demonstraram que sua sobrevivência depende também de outras práticas cotidianas ligadas ao extrativismo. A fim de construir os barcos, suas casas, as cercas dos quintais, assim como assar alimentos - que muitas vezes são feitos para o comércio - extraem a madeira da região. Com ela fazem o carvão de seus fornos, extraem as palhas para a cobertura de casas e barracões e as raízes com as quais desenvolvem medicamentos naturais e frutos para alimentação diária.

A observação e o diálogo com os colaboradores nos permitiram perceber a socialização dos saberes e técnicas em torno da exploração do babaçu e do buriti, de onde extraem o óleo e aproveitam a palha para fazer cordas, tapetes e escovas, e da carnaúba, esta última chamada como "árvore da vida", da qual, segundo seus relatos, tudo se aproveita.

Além dos ofícios, suas narrativas também revelaram histórias fantásticas que permeiam as atividades empreendidas no rio e na comunidade. Personagens místicos, tradicionalmente lembrados por velhos e crianças em rodas de conversa, emergiram como elementos da identidade das Canárias: pequenos monstros que saem dos cajueiros; figuras sem forma que aparecem durante as pescarias para atrapalhá-los; vozes que conversam com os pescadores e os amedrontam. Assim como eles, são famosos na memória coletiva o "cabeça-de-cuia", amaldiçoado por sua mãe e que aparece nos rios para assustar as mulheres; o "lobisomem", que aparece na comunidade também em forma de outros animais, como porco e que alguns membros conseguem apontar como encarnados em seus vizinhos; a misteriosa mulher que chora com o filho nos braços em algumas noites; e, enfim, "o gritador", homem que provoca medo e também risos sobre sua performance nos rios e nas ruas.

Contadas em roda, essas histórias são sempre legitimadas pela confirmação do companheiro, narradas de forma coletiva, em que falas são complementadas, entre expressões de medo e risos. Delas extraem-se ensinamentos aos mais novos sobre os perigos do mar e sobre a coragem dos pescadores, assim como a importância da proteção divina.

A mística, a religiosidade e as festas foram lembradas como mecanismos de unidade entre os ribeirinhos. Os festejos atraem membros de outras regiões, em busca da participação na celebração religiosa ministrada por padres que vêm de Araioses. A igreja se localiza na praça central, local em que os pescadores também costumam se encontrar para tecer e consertar suas redes, para beber e conversar, enquanto seus filhos brincam. Ali, além da missa, ocorrem danças no final da noite, a procissão e o leilão, quando religião e diversão se confundem. No leilão, em especial, segundo os entrevistados, cada família costuma doar animais, como porcos e galinhas, comidas como pães e bolos, ou até mesmo pequenos artefatos produzidos por eles ou heranças de parentes, para que sejam leiloados e o dinheiro seja revertido à Igreja. A prenda - que eles chamam de "joia" - muitas vezes é resgatada pelo próprio doador, o que significa para eles contribuir duas vezes com a comunidade.

Ainda há outra festividade importante que é a comemoração do aniversário das Canárias no dia 14 de novembro, evento organizado pela Associação de Moradores e pela Associação de Pescadores locais. Nesse momento, também acontecem a celebração da missa, algumas gincanas e uma regata de canoas das quais participam pescadores de várias regiões ao redor, atraindo povoados vizinhos e turistas.

5 Embora considerado importante, esse aspecto não será discutido em profundidade aqui, pois desviaria o sentido da temática proposta por esse artigo. 
A religiosidade nos festejos é aspecto presente em todas as narrativas, tornando-se marca coletiva. Em meio a tantas identidades possíveis, num mundo marcado por apropriações, aceleração do tempo e intromissão de pessoas que não pertencem à comunidade nestas festas, os narradores procuraram apontar uma memória coletiva de solidariedade como signo de seus hábitos e convivência, assim como elemento de resistência, mostrando o que Zygmunt Bauman (2005) chama de um pertencimento solidário, em oposição à dissolução do espírito fraternal dado pelo tempo capitalista que individualiza e fragmenta.

As entrevistas permitiram perceber que a cultura imaterial não está dissociada da produção de bens materiais, apropriados e significados pelos moradores dessa região, buscando valorizar o caráter vivo e contínuo, tirando-os de sua condição de invisibilidade histórica. Falar do rio e da natureza circundante é chamar a atenção para a relação intrínseca entre o ambiente e os narradores, assim como natureza e cultura não se opõem, mas se integram e se influenciam dialeticamente. Essa relação é ininterrupta e é reinventada a cada geração já que ambas são dinâmicas e vivas. Como afirma Sandra C.A. Pelegrini,

\begin{abstract}
Não se pode negligenciar a complexidade adquirida pela temática do patrimônio natural, quando esta se articula à noção de paisagem, uma vez que ela incorpora as relações do homem com o meio, e ainda sugere que os "modos" ou "gêneros" do viver humano produzem "paisagens culturais". As singularidades relacionais entre as culturas e o meio ambiente definem, conforme os fundamentos da geografia cultural, os traços da própria paisagem e a distinguem de outros espaços, determinando o seu geni'us loci, ou seja, a “alma do lugar”. (PELEGRINI, 2006a: p.63)
\end{abstract}

Desta forma, trabalhar com patrimônio cultural material e imaterial não é considerar natureza e cultura como aspectos antagônicos, mas sim engendrados num contínuo processo de transformação. Os bens imateriais permanecem na memória e têm sentido na identidade coletiva na medida em que mantêm vínculos identitários. Ao relatarem sobre sua convivência com a beleza e o perigo do Rio Parnaíba e do mar, sobre a produção dos barcos, o artesanato com a carnaúba e como os filhos colocam em prática o aprendizado de tecer redes desde a mais tenra idade, os sujeitos reconhecem na paisagem, na história e no tempo o elo emocional e as experiências que os fazem se sentir parte de uma dinâmica específica da população ribeirinha.

Segundo Diegues, o "conhecimento tradicional é definido como o conjunto de saberes e saber-fazer a respeito do mundo natural, sobrenatural, transmitido oralmente de geração em geração" (1999, p. 31). Mais do que isso, os relatos sobre os saberes e fazeres mostram o interesse em debater sobre a conservação ou não de certas tradições na comunidade.

\title{
Narrativas de vida, história pública e políticas públicas
}

De acordo com os postulados da Carta de Macchu Picchu, formulada em 1997, as práticas de preservação e conservação de patrimônios das comunidades tradicionais deveriam levar em conta as transformações que afetariam suas experiências e saberes. Sobre isso, Sandra Pelegrini que

as tarefas de conservação e restauração deveriam inserir-se no processo de desenvolvimento urbano, abarcando soluções legais capazes de inibir a contaminação ambiental, incrementar a disponibilização do solo urbano, visando satisfazer as necessidades coletivas e estimular o transporte público em massa. Ao admitir que a identidade de uma cidade não era determinada apenas pela sua estrutura física, mas também por suas características sociológicas, o documento propunha que se preservasse e conservasse não apenas o patrimônio monumental, mas que se assumisse a defesa do patrimônio cultural conservando os valores (...) de fundamental importância para afirmar a personalidade comunal ou nacional e/ou aqueles que têm autêntico significado para a cultura em geral. (PELEGRINI, 2006b: p.60)

Nesse sentido, o patrimônio passou a ser entendido como todo conhecimento que uma sociedade produz e possui de si mesma, assim como as formas de se conceber e de se posicionar diante de outras, sua maneira de existir, acreditar, manifestar seus saberes, organizar suas cerimônias coletivas, suas festividades, a manutenção de suas tradições, o uso de suas técnicas e experiências, enfim, tudo aquilo que tem significado e dá sentido à sua vida individual e à identidade coletiva.

Pescadores (as), barqueiros, artesãos e artesãs demonstraram posicionamento político diante de órgãos, de especialistas e intelectuais que intervêm continuamente na vivência e nos significados do mundo natural e sobrenatural da comunidade, por meio de políticas públicas que, segundo eles, deixaram de con- 
siderar necessidades emergenciais na ilha, como a invasão das dunas em suas casas, a falta de atendimento médico (apenas alguns dias durante e nenhum no final de semana), a ausência de postos de saúde e a frágil estrutura das escolas.

Desde os primeiros encontros, um elemento emergiu das narrativas dos moradores das Canárias: a necessidade de que a comunidade seja ouvida para a solução de problemas que afligem seus habitantes. $\mathrm{O}$ objetivo da pesquisa que era, em princípio, realizar um inventário do patrimônio imaterial e ambiental, passou a considerar também as questões políticas que perpassavam os relatos sobre o sentido do que se desejava ver conservado, a interferência de órgãos públicos e particulares na dinâmica de suas vidas, mais do que a tradição de certas práticas e da preservação do meio ambiente para os moradores.

A escuta, portanto, passou a considerar não apenas critérios de observação e análise de manifestações culturais, do trabalho e das festividades, mas levou em conta a sensibilidade para perceber como o tempo, o gênero, $\mathrm{o}$ papel social e geracional e a política poderiam interferir nas memórias, nas negociações possíveis entre a coletividade, em que determinadas narrativas acabavam por se sobrepor a outras. Trabalhar com história oral significa ouvir com delicadeza também sobre as frustrações e desejos constantemente construídos e negociados pela comunidade.

$\mathrm{Na}$ convivência com pescadores, artesãos e barqueiros, foi possível perceber a existência de posicionamentos políticos quanto ao significado das políticas públicas ali estabelecidas pelos órgãos como Ibama e Incra, no sentido de organizar determinados usos e costumes dos ribeirinhos e direcionar suas relações com a natureza. Os relatos apontaram, por exemplo, para o impedimento de continuarem a pescar em determinadas épocas e a restrição ao uso da madeira para a construção de casas, sem a consulta ou o debate coletivo.

Mais do que um inventário, de caráter quantitativo, a tradição oral e as histórias de vida salientaram a preocupação qualitativa, levando em conta as subjetividades, as relações emocionais com a história e a memória coletiva, com a produção de bens materiais, com o meio ambiente, elementos continuamente recriados e fortalecedores da identidade das Canárias.

Zygmunt Bauman (2005) afirmou que habitar um lugar não é o suficiente para que as pessoas se sintam pertencentes a uma comunidade e a um território cultural e que as explicações acadêmicas, governamentais ou do senso comum, exteriores à vivência cotidiana, podem se mostrar estranhas aos próprios membros de um determinado grupo. Ao narrarem sobre suas experiências, a identidade vai se delineando, muitas vezes por meio do rompimento ou da rejeição a definições exógenas e deterministas com relação aos sujeitos que contam. A escuta atenta proporcionou perceber que os colaboradores pedem para si a oportunidade para se autodefinirem e apontarem aquilo que para eles importa debater, proteger e exigir.

Um dos problemas apontados por eles está relacionado ao fato de que a renda de parte dos grupos tradicionais das Canárias depende, em parte, da captura do caranguejo uçá. O ICMBio, ligado ao Ibama, realiza projeto de remanejamento dessa atividade nos manguezais ${ }^{6}$. O fato de boa parte desses trabalhadores ser muito pobre e de ter pouco acesso a serviços sociais básicos, como saúde e educação, coloca-os numa relação de dependência muito grande com relação a essa prática. Por não serem organizados em associações, como os pescadores são, e por terem escolaridade baixa, são muitas vezes marginalizados pela própria comunidade.

O limite dado ao trabalho realizado por eles pelos órgãos que se preocupam com a extinção dessa espécie de caranguejo nem sempre é bem-visto ou compreendido pelos catadores como algo que vá contribuir para a melhoria de sua vida. Muitas vezes, enxergam a presença dos representantes de Organizações Não Governamentais e representantes do governo como ingerência indevida sobre suas vidas. Como não são registrados em associações de trabalhadores, a tendência é que eles não tenham garantidos os seus direitos, como por exemplo o benefício dado aos pescadores pelo governo federal em períodos de defeso, ou seja, quando os peixes precisam se reproduzir e a pesca é proibida.

A presença de atravessadores, devido ao desenvolvimento do turismo que exclui a comunidade, foi outro fator constantemente apresentado como problemático. O crescimento de bares e restaurante à beira do Rio Parnaíba faz com que a demanda por peixes, caranguejos e mariscos aumente, atraindo mercadores que pagam valores muito baixos aos moradores das Canárias pelo resultado de seu trabalho. A hiperexploração, sem nenhuma regulamentação do comércio e do turismo de base na região, é amplamente criticada pelos entrevistados.

6 Projeto do ICMBio Ministério do Meio Ambiente. Conservação e Uso Sustentável Efetivos de Ecossistemas Manguezais no Brasil (PIMS 3280). Projeto do Atlas no 00055992. Programa das Nações Unidas para o Desenvolvimento. Fundo para o Meio Ambiente Mundial. Ministério do Meio Ambiente (MMA) da República Federativa do Brasil. 
Além desse aspecto, os narradores abordaram outros problemas como o acesso restrito à terra, que não pode mais ser vendida na região de preservação, e a proibição quanto à extração de madeira para fazer o carvão e a construção de casa de alvenaria, o que, segundo o Incra, contribuem para o desmatamento que provoca o assoreamento do Rio Parnaíba pelo avanço das dunas. Essas interferências externas são interpretadas por alguns moradores como prejuízo a sua vida, rompendo uma tradição da comunidade, como determinações autoritárias. São decisões políticas que nem sempre encontram ressonância na comunidade, ciente de sua exclusão no processo decisório e também dos benefícios da chamada preservação.

Outros elementos foram apontados pelos narradores, demonstrando a ausência de políticas públicas democráticas, que correspondam de fato a suas necessidades: a falta de água tratada para consumo, tendo que recorrer aos poços com água salobra, o que adoece principalmente crianças e velhos. A chegada da energia elétrica, um benefício reconhecido por todos que até pouco tempo utilizavam a lamparina a querosene, também tem seu ponto negativo, como o distanciamento provocado entre vizinhos, que passaram a se preocupar com a televisão, celulares e com os computadores. A dissolução da tradicional conversa ao pé do portão, assim como a ingerência econômica sobre suas festas religiosas, foi vista como um problema que afeta laços de companheirismo e solidariedade dos narradores, marca identitária que se quer conservar.

A abertura do comércio com refrigeradores, a criação de pousadas para turismo e o congelamento de comida - dentre eles o próprio peixe - foram problemas que os narradores levantaram, relacionando-os à chegada de pessoas de fora, com valores diferentes daqueles transmitidos pela oralidade e convivência coletiva. O aumento da violência, as mudanças nos costumes e na qualidade dos alimentos, com o acesso a comidas enlatadas e congeladas, sem que haja alterações nas políticas públicas quanto a questões da saúde, também põem em dúvida a ingerência externa sobre suas vidas.

Os entrevistados apontaram para a divisão política na direção das associações de moradores e pescadores e na aceitação ou não dos encaminhamentos propostos por especialistas que, para eles, estão fora de sua experiência cotidiana. O que fica claro até o momento é o desejo de serem ouvidos, sugerindo a realização de reuniões e a criação de oficinas, pelas quais possam se manifestar quanto ao futuro de suas práticas. Ao aceitarem o diálogo conosco sobre suas vidas, expressaram a vontade de que pesquisadores atuem como mediadores entre comunidade e especialistas, no sentido de ampliar as formas de pensar seu patrimônio cultural e suas necessidades de sobrevivência. Cobraram não só a posição do Estado, mas também da Academia enquanto espaço de erudição e reflexão política. Manifestaram o desejo de que suas histórias sejam conhecidas, publicizadas, a fim de que se garanta um processo mais democrático quanto à tomada de decisões e benefícios.

\section{Considerações finais}

A história oral pode promover um trabalho em colaboração, participativo, em busca de narrativas que nos revelem modos de vida, sentimentos de pertença, vontades de preservar certos elementos identitários dos ribeirinhos e, por conseguinte, as demandas por políticas públicas que possam ir ao encontro de suas necessidades e singularidades. Registrar diferentes histórias, práticas e saberes em suas diversas versões, transmitidos coletivamente, pode significar dar amplo conhecimento público, registrar memórias para conservar saberes e ampliar a participação das comunidades nas decisões sobre suas próprias vidas.

Cada relato dos pescadores, catadores de caranguejo, marisqueiras e artesãos deve ser entendido na relação com o espaço, o ambiente, as pessoas, os elementos concretos e simbólicos, o imaginário sobre o rio, a terra e o mar, sua relação com a vida que se constrói todos os dias, a vida que se constitui ao seu redor, a linguagem e valores que se constroem a partir do meio ambiente. Suas preocupações apresentam racionalidade diferenciada, muitas vezes, de intelectuais que pensam a questão da preservação ambiental descolada das demandas sociais e da sobrevivência comunitária.

Os moradores entrevistados mostraram, em sua maioria, que o saber tradicional e o técnico/acadêmico não podem, em momento algum, ser comparados - por se tratarem de origens diferentes - mas nem por isso podem ser pensados separadamente na reflexão sobre as políticas públicas que atendam às necessidades populares.

Num contexto de apropriação industrial, padronização e comercialização de bens das comunidades tradicionais e de não reconhecimento de sua autoria coletiva, a memória e a narrativa dos pescadores tornam-se ato de afirmação da própria história e de uso das palavras como denúncia, escolha e necessidade. Poder verbalizar sua realidade significa empoderamento, selecionando e decidindo sobre o que é importante para ser publicizado e preservado. 
O trabalho com a memória coletiva, a cultura intangível e a tradição oral, envolvendo a decisão sobre qual patrimônio se quer conservado, assim como o que deve ser mudado no cotidiano, pode resultar na construção de políticas públicas que contribuam para a cidadania dos habitantes das Canárias, preocupados com a manutenção daquilo que significa suas vidas e com o crescimento da intervenção externa sobre elas sem consultá-los.

Os narradores não são informantes, são intérpretes de seus próprios bens e valores, realizam leituras, nomeiam e agregam importância aos seus afazeres. Para reconhecer o patrimônio é preciso, antes, conhecer, inventariar e tornar público o que eles desejam conservar. Também pensar sobre a prática de empoderamento da comunidade, seu reconhecimento como agrupamento, como pessoas que fazem história e pensam sobre ela. São sujeitos pensantes, que não apenas nos fornecem dados sobre a história do lugar, as tradições e a vivência, como aconselham, significam cada prática e as relações em torno delas. Ouvi-los implica romper com a posição de onisciência intelectual e a separação entre aqueles que narram e informam (os entrevistados) e aqueles que analisam (os intelectuais das instituições).
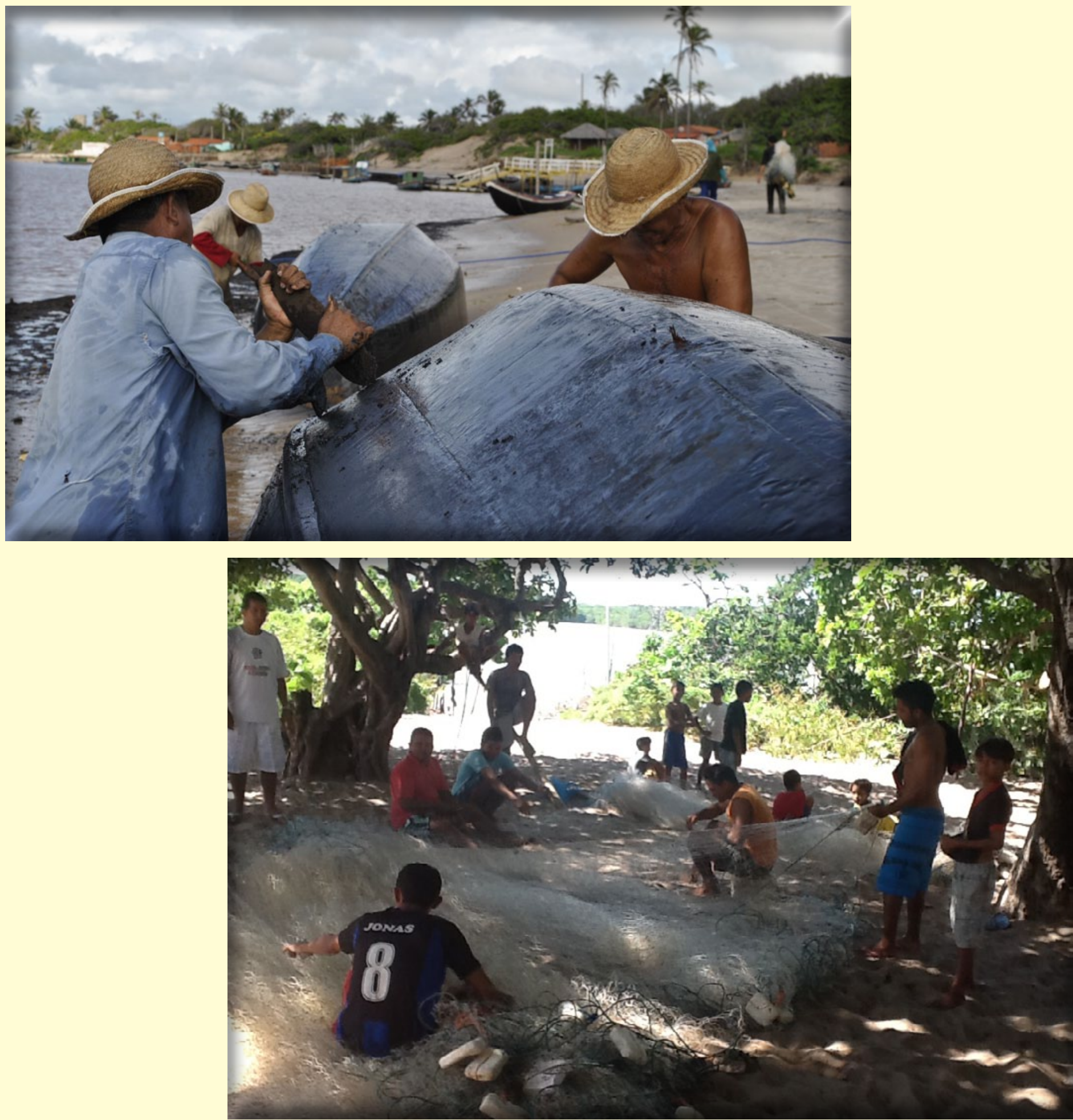

Fotos: Acervo do Grupo Cidade, Cultura e Identidade (Uespi) 
Como afirmou Alessandro Portelli (1996), os fatos selecionados pela memória e narrados trazem consigo leitura e versões de mundo, que se iniciam nas palavras do narrador e não na análise acadêmica do pesquisador. As marcas apontadas pela coletividade das Canárias como passíveis de valorização e como parte intrínseca de suas vidas mudam a perspectiva e o critério sobre os bens a ser conservados e as necessidades a ser atendidas, para além daqueles atribuídos pelas instituições governamentais e especialistas. Não cabe a estes últimos a exclusividade para decidir sobre o que, por que e como proteger.

Diante das demandas comunitárias os critérios de raridade, urgência, autenticidade e universalidade, utilizados para entender o patrimônio, ganham novas leituras a partir das referências culturais, ligadas à afetividade e ao pertencimento das comunidades. Os bens imateriais podem ser inventariados e registrados, mas se não fizerem parte da vivência e não significarem continuamente na coletividade, não sobreviverão; sofrerão a diluição no tempo e na memória. Dar visibilidade, mapear o território em que os afazeres se dão, a identificação dos bens valiosos aos diferentes grupos sociais nas Ilhas das Canárias, deve ser resultado da interação participativa e democrática, para a qual a história oral deve contribuir.

\section{Referências bibliográficas}

AMOROZO, M. C. M. 1996. A abordagem etnobotânica na Pesquisa de Plantas medicinais. Em Di Stasi LC (Org.) Plantas medicinais: arte e ciência, um guia de estudo interdisciplinar. EDUSP. São Paulo.

BAUMAN, Zygmunt. 2005. Identidade. Rio de Janeiro: Zahar.

DIEGUES, A.C. et al. (Org.). 1999. Biodiversidade e comunidades tradicionais no Brasil. Brasilia: Ministério do Meio Ambiente; São Paulo: USP.

GONÇALVES, José R. Santos. 2005. Ressonância, materialidade e subjetividade: as culturas como patrimônio. Horizontes Antropológicos, Porto Alegre, ano 11, n. 23, jan/jun, p. 15-36.

IPHAN. 2000. Inventário Nacional de Referencias Culturais/INRC. Brasília:Iphan. http://portal.iphan.gov.br/ portal $/$ montarPaginaSecao.do?id $=13493 \&$ retorno $=$ paginaIpha

PELEGRINI, Sandra C. A. 2006a. Cultura e natureza: os desafios das práticas preservacionistas na esfera do patrimônio cultural e ambiental. Revista Brasileira de História, v.26, n.52, São Paulo: Universidade de São Paulo.

2006b. O patrimônio cultural no discurso e na lei: trajetórias do debate sobre a preservação no Brasil. Revista Patrimônio e Memória. UNESP - FCLAs - CEDAP, v.2, n.2, p.54-77.

POLLAK, Michael. 1992. Memória e identidade social. Estudos Históricos, Rio de Janeiro, 5 (10), p. 200-212.

PORTELLI, Alessandro. 1996. A Filosofia e os Fatos. Revista Tempo, Rio de Janeiro, v.1, n.2, p.59-72. 